\title{
Technical note: In vitro total gas and methane production measurements from closed or vented rumen batch culture systems
}

\author{
M. Cattani, ${ }^{*}$ F. Tagliapietra,† L. Maccarana, ${ }^{*}$ H. H. Hansen,‡ L. Bailoni, ${ }^{\star 1}$ and S. Schiavon† \\ *Department of Comparative Biomedicine and Food Science (BCA), University of Padova, Viale dell'Università 16, 35020, Legnaro (PD), Italy \\ †Department of Agronomy, Food, Natural Resources, Animals and Environment (DAFNAE), University of Padova, Viale dell'Università 16, 35020, \\ Legnaro (PD), Italy \\ ‡Department of Large Animal Sciences, University of Copenhagen, Grønnegårdsvej 2, 1870 Frederiksberg, Denmark
}

\begin{abstract}
This study compared measured gas production (GP) and computed $\mathrm{CH}_{4}$ production values provided by closed or vented bottles connected to gas collection bags. Two forages and 3 concentrates were incubated. Two incubations were conducted, where the 5 feeds were tested in 3 replicates in closed or vented bottles, plus 4 blanks, for a total of 64 bottles. Half of the bottles were not vented, and the others were vented at a fixed pressure $(6.8 \mathrm{kPa})$ and gas was collected into one gas collection bag connected to each bottle. Each bottle $(317 \mathrm{~mL})$ was filled with $0.4000 \pm 0.0010$ $\mathrm{g}$ of feed sample and $60 \mathrm{~mL}$ of buffered rumen fluid (headspace volume $=257 \mathrm{~mL}$ ) and incubated at $39.0^{\circ} \mathrm{C}$ for $24 \mathrm{~h}$. At $24 \mathrm{~h}$, gas samples were collected from the headspace of closed bottles or from headspace and bags of vented bottles and analyzed for $\mathrm{CH}_{4}$ concentration. Volumes of GP at $24 \mathrm{~h}$ were corrected for the gas dissolved in the fermentation fluid, according to Henry's law of gas solubility. Methane concentration $(\mathrm{mL} / 100$ $\mathrm{mL}$ of GP) was measured and $\mathrm{CH}_{4}$ production $(\mathrm{mL} / \mathrm{g}$ of incubated DM) was computed using corrected or uncorrected GP values. Data were analyzed for the effect of venting technique $(\mathrm{T})$, feed $(\mathrm{F})$, interaction between venting technique and feed $(\mathrm{T} \times \mathrm{F})$, and incubation run as a random factor. Closed bottles provided lower uncorrected GP (-18\%) compared with vented bottles, especially for concentrates. Correction for dissolved gas reduced but did not remove differences between techniques, and closed bottles $(+25 \mathrm{~mL}$ of gas/g of incubated DM) had a greater magnitude of variation than did vented bottles $(+1 \mathrm{~mL}$ of gas/g of incubated $\mathrm{DM})$. Feeds differed in uncorrected and corrected GP, but the ranking was the same for the 2 techniques. The $\mathrm{T}$ $\times \mathrm{F}$ interaction influenced uncorrected GP values, but this effect disappeared after correction. Closed bottles provided uncorrected $\mathrm{CH}_{4}$ concentrations $23 \%$ greater
\end{abstract}

Received September 6, 2013.

Accepted November 10, 2013.

${ }^{1}$ Corresponding author: lucia.bailoni@unipd.it than that of vented bottles. Correction reduced but did not remove this difference. Methane concentration was influenced by feed but not by the $\mathrm{T} \times \mathrm{F}$ interaction. Corrected $\mathrm{CH}_{4}$ production was influenced by feed, but not by venting technique or the $\mathrm{T} \times \mathrm{F}$ interaction. Closed bottles provide good measurements of $\mathrm{CH}_{4}$ production but not of GP. Venting of bottles at low pressure permits a reliable evaluation of total GP and $\mathrm{CH}_{4}$ production.

Key words: in vitro gas production, methane, venting technique, rumen fermentation

\section{Technical Note}

Several batch culture systems are available to measure gas production (GP) during in vitro rumen fermentation. Many of these systems are equipped with devices for gas venting at fixed interval times (Theodorou et al., 1994) or at a fixed pressure (Cone et al., 1996; Davies et al., 2000; Calabrò et al., 2005; Tagliapietra et al., 2010). Gas venting is recommended to avoid pressure conditions that cause a partial dissolution of $\mathrm{CO}_{2}$ in the fermentation fluid, with a consequent underestimation of total GP (Tagliapietra et al., 2010) and possible disturbance of microbial activity (Theodorou et al., 1994) and thereby $\mathrm{CH}_{4}$ production. Vented GP systems are less frequently used to evaluate the composition of gas produced, because the vented gas must be collected in bags that are leak proof and are not permeable to $\mathrm{CO}_{2}$ or $\mathrm{CH}_{4}$. Closed GP systems are more commonly used for measurements of $\mathrm{CH}_{4}$ production. With a closed system, the gas is not vented and remains in the bottle headspace until the time of collection for analysis (Pell and Schofield, 1993; Getachew et al., 2005; Pellikaan et al., 2011). However, the gas pressure generated in the headspace will cause a partial dissolving of $\mathrm{CO}_{2}$ in the fermentation fluid that can alter the GP composition, so that a correction for solubilized $\mathrm{CO}_{2}$ is required. The difference in $\mathrm{CO}_{2}$ concentration in the headspace and the amount dissolved in the fluid can, in turn, alter the $\mathrm{CH}_{4}$ concentration in the collected gas (Patra and $\mathrm{Yu}, 2013)$. The objective of the current study was to 
compare, also in term of repeatability, the effects of 2 systems of gas collection, one based on closed fermentation bottles and one based on vented bottles connected to tight plastic bags, on total GP, gas composition and $\mathrm{CH}_{4}$ production computed from GP and gas composition measures.

Two forages (meadow hay and ryegrass hay) and 3 concentrates (corn grain, dry sugar beet pulp, and expeller flaxseed) were incubated. The 5 feeds were selected to cover a large variability in chemical composition and to generate different pressure conditions in the bottle headspace during incubation. All feeds were provided by a dairy farm located in the province of Brescia (Italy). About $1 \mathrm{~kg}$ of each feed was ground by a hammer mill with a screen size of $1 \mathrm{~mm}$. From each feed, 15 subsamples were prepared: 12 samples were used for the incubations (6 for each run) and the remaining 3 for chemical analysis. Feeds were analyzed in 3 replicates for proximate composition (AOAC International, 2012). The NDF, inclusive of residual ash, was determined with $\alpha$-amylase and sodium sulfite (Mertens, 2002) using the Ankom ${ }^{220}$ Fiber Analyzer (Ankom Technology, Macedon, NY). The ADF, inclusive of residual ash, and sulfuric acid lignin $\left[\operatorname{lignin}_{(\mathrm{sa})}\right]$ contents were sequentially determined according to Robertson and Van Soest (1981). Chemical composition of the 5 feeds is reported in Table 1 .

Incubations were conducted following the procedures detailed by Tagliapietra et al. (2012), according to a factorial design where the 5 feeds were simultaneously tested using the 2 techniques, closed or vented bottles, in each of 2 consecutive incubations. In each incubation, each feed was tested with 3 replications (using 3 bottles) plus 2 blanks containing only the buffered rumen fluid, for a total of 32 bottles. Rumen fluid was collected using an esophageal probe (Tagliapietra et al., 2012) from 3 intact, dry Holstein cows fed hay ad libitum and $2.5 \mathrm{~kg} / \mathrm{d}$ of concentrates $(0.5 \mathrm{~kg}$ of dry sugar beet pulp, $1 \mathrm{~kg}$ of corn grain, and $1 \mathrm{~kg}$ of sunflower meal) for $3 \mathrm{wk}$ preceding fluid collection. Differences between fluid collected with the probe instead of fluid collected from fistulated cows were not considered rel- evant for the comparative purposes of this work. The rumen fluid collected from the 3 cows was poured into 2 thermal flasks preheated to $39 \pm 0.5^{\circ} \mathrm{C}$ and immediately transferred to the laboratory. The rumen fluid collected from the 3 cows was mixed, filtered through 3 layers of cheesecloth to eliminate feed particles, and then mixed with the buffer mineral solution in a $1: 2$ ratio (Menke and Steingass, 1988). All operations were conducted under anaerobic conditions by flushing with $\mathrm{CO}_{2}$, and the time required for all operations was less than $30 \mathrm{~min}$. Each bottle $(317 \mathrm{~mL})$ was filled with $0.4000 \pm 0.0010 \mathrm{~g}$ of feed sample and $60 \mathrm{~mL}$ of buffered rumen fluid (Menke and Steingass, 1988), leaving a corresponding headspace volume of $257 \mathrm{~mL}$. Bottles, placed into an incubator at $39.0 \pm 0.5^{\circ} \mathrm{C}$ for $24 \mathrm{~h}$, were not agitated during incubation. All bottles used in this experiment were from the A\# ${ }^{\mathrm{RF}}$ GP System (Ankom Technology), which was successfully tested for absence of gas pressure variation $(70 \mathrm{kPa})$ over a period of 7 d. For the purpose of the current study, half of the bottles were not vented during incubation, to simulate the closed system technique, and the others were connected with gas-proof Tygon tubing (Saint-Gobain Performance Plastics, Paris, France) to 1-L gas sample bags (standard FlexFoil, SKC Inc., Pennsylvania, PA) and automatically vented by an open-closed valve (model LHLX0502100BC, The Lee Co., Essex, CT) when headspace pressure reached $6.8 \mathrm{kPa}$. This pressure corresponded to $17 \mathrm{~mL}$ for a headspace volume of $257 \mathrm{~mL}$. All gas sample bags were previously vacuumsealed to eliminate possible traces of air. The closed and vented bottles were equipped with pressure sensors (pressure range: -69 to $+3,447 \mathrm{kPa}$; resolution: 0.27 $\mathrm{kPa}$; accuracy: \pm 0.01 of measured value) that measured the pressure inside the bottles every $1 \mathrm{~min}$. At the end of incubation $(24 \mathrm{~h})$, gas was collected with a $10-\mathrm{mL}$, gas-tight syringe (Artsana S.p.A., Como, Italy) from the headspace of each closed bottle, and from the headspace and gas-tight plastic bag for each vented bottle. At sampling, the syringe was flushed to ensure the collection of a homogeneous sample, which was immediately injected into a 9-mL Vacuette (Greiner Bio-One

Table 1. Dry matter $(\mathrm{g} / \mathrm{kg})$ contents and chemical composition $(\mathrm{g} / \mathrm{kg}$ of $\mathrm{DM})$ of the feeds $(\mathrm{n}=3)$

\begin{tabular}{lccccrrr}
\hline Feed & DM & NDF & ADF & Lignin $_{(\mathrm{sa})}{ }^{1}$ & CP & Ether extract $^{\text {Ash }}$ & NSC $^{2}$ \\
\hline Corn grain & 900 & 106 & 23 & $-{ }^{3}$ & 93 & 37 & 15 \\
Dry sugar beet pulp & 935 & 443 & 250 & 29 & 95 & 60 & 749 \\
Flaxseed expeller & 923 & 260 & 118 & 40 & 375 & 91 & 51 \\
Meadow hay & 893 & 435 & 305 & 60 & 90 & 15 & 89 \\
Ryegrass hay & 888 & 591 & 347 & 30 & 149 & 15 & 36 \\
\hline
\end{tabular}

${ }^{1} \operatorname{Lignin}_{(\mathrm{sa})}=$ sulfuric acid lignin.

${ }^{2} \mathrm{NSC}=$ nonstructural carbohydrates, computed as $(100-\mathrm{NDF}-\mathrm{CP}-$ ether extract - ash $)$.

${ }^{3}$ Amount not measurable. 
GmbH, Kremsmünster, Austria). From each Vacuette, an aliquot of $2.7 \mu \mathrm{L}$ of gas was extracted with a gastight syringe (1701N, Hamilton, Bonaduz, Switzerland) and immediately analyzed for $\mathrm{CH}_{4}$ concentration by GC with flame ionization detection (8000 TOP, Thermo Quest, Rodano, Milano, Italy) using a 30-m stainless steel column (GS-CarbonPLOT, Agilent Technologies, Milano, Italy) and hydrogen as carrier gas (flow rate: $1.8 \mathrm{~mL} / \mathrm{min}$; isothermal oven temperature: $\left.150^{\circ} \mathrm{C}\right) . \mathrm{A}$ 6 -point standard curve was generated by mixing known volumes of $\mathrm{CH}_{4}$ (99.5\% pure, SAPIO s.r.l., Monza, Italy) with known volumes of air using the same graduated gas-tight syringe (1701N, Hamilton). The 6 gas mixtures used for calibration contained 10, 15, 20, 25, 50, and $100 \mathrm{~mL}$ of $\mathrm{CH}_{4} / \mathrm{L}$. The calibration regression had an $\mathrm{R}^{2}>0.99$.

Cumulative pressure values were calculated from measured pressure changes at given times, converted to units of volume (GP, mL) using the ideal gas law, and expressed per gram of incubated DM. Bottles with only rumen fluid and buffer (blanks) produced minimal amounts of gas (on average $7.2 \pm 2.2 \mathrm{~mL}$ ) and therefore were not used in further calculations. The GP volumes were corrected or not for the amount of dissolved gas computed according to Henry's law, from total gas pressure and $\mathrm{CO}_{2}$ solubility, as described by Pell and Schofield (1993). Corrections for solubilized $\mathrm{CO}_{2}$ are hereafter called adjustments. The total $\mathrm{CH}_{4}$ production achieved from closed bottles was computed according to Lopez et al. (2007) as follows: $\mathrm{CH}_{4}$ concentration in the headspace $\times$ [headspace volume $(257 \mathrm{~mL})+$ total GP volume $(\mathrm{mL})]$. Methane production from vented bottles was computed as $\mathrm{CH}_{4}$ concentration in the headspace $\times$ headspace volume $(257 \mathrm{~mL})+\mathrm{CH}_{4}$ concentration in the gas bag $\times$ total GP volume $(\mathrm{mL})$. The $\mathrm{CH}_{4}$ concentration and calculated production were both computed using adjusted and unadjusted total GP volumes.

Data were analyzed using PROC MIXED of SAS Institute (2007) with a model that included, as fixed factors, the venting technique $(\mathbf{T} ; 1 \mathrm{df})$, the feed $(\mathbf{F} ; 4$ df), the interaction between venting technique and feed $(\mathrm{T} \times \mathrm{F} ; 4 \mathrm{df})$, and as a random variable the incubation run (1 df). A model considering all variables as random was used to estimate the variance components. The repeatability, defined as the value below which the absolute difference between 2 single measures obtained with the same technique and under the same conditions (same incubation run, same feed) is expected with a $95 \%$ probability (IOS, 1994), was computed as $2 \sqrt{2 \sigma_{e}^{2}}$, where $\sigma_{e}^{2}$ is the residual variance.

Closed bottles produced lower (approximately $-18 \%$; $P<0.001$ ) amounts of unadjusted GP compared with vented bottles (Table 2). The differences were particu- larly pronounced for highly fermentable substrates such as corn grain $(-56 \mathrm{~mL}$ of gas/g of incubated DM; $P<$ $0.001)$ and dry sugar beet pulp $(-54 \mathrm{~mL}$ of gas/g of incubated DM; $P<0.001$ ), whereas smaller, but still significant, differences were found for flaxseed expeller $(-26 \mathrm{~mL}$ of gas/g of incubated DM; $P<0.001)$, meadow hay $(-26 \mathrm{~mL}$ of gas/g of incubated DM; $P<0.001)$, and ryegrass hay $(-17 \mathrm{~mL}$ of gas/g of incubated DM; $P$ $=0.005$; data not shown). Values of repeatability were 5.9 and $8.9 \mathrm{~mL}$ of gas/g of incubated DM for closed and vented bottles, respectively. The $\mathrm{T} \times \mathrm{F}$ interaction $(P$ $<0.001$ ) was found to influence the unadjusted values of GP, but this interaction effect was not significant when GP values were adjusted for dissolved gas $(P=$ 0.25 ). After adjustment for dissolved gas, the GP values provided by the 2 techniques continued to be different $(P<0.001)$, even if this difference was numerically smaller. The magnitude of such adjustment was notable for closed bottles where a considerable increase of GP values (on average $+25 \mathrm{~mL}$ of gas/g of incubated $\mathrm{DM}$ ) was found, whereas the adjustment value was negligible for vented bottles (on average $+1 \mathrm{~mL}$ of gas/g of incubated DM; Figure 1a and b). Feeds differed for unadjusted and adjusted GP $(P<0.001)$, even though the ranking for GP was unaffected by venting. Values of repeatability for adjusted GP were 6.3 and $9.0 \mathrm{~mL}$ of gas/g of incubated DM for closed and vented bottles, respectively. The 2 techniques provided different $(P$ $<0.001)$ unadjusted $\mathrm{CH}_{4}$ concentration $(\mathrm{mL} / 100 \mathrm{~mL}$ of GP), with values $23 \%$ greater for closed compared with vented bottles. The adjustment for dissolved GP reduced but did not completely remove this difference $(P=0.002)$. Methane concentration was influenced by feed $(P=0.005)$, but not by the $\mathrm{T} \times \mathrm{F}$ interaction $(P=0.57)$. Unadjusted or adjusted $\mathrm{CH}_{4}$ production $(\mathrm{mL} /$ of incubated DM) was influenced by feed $(P<$ 0.001 ) but not by the venting technique or the $\mathrm{T} \times \mathrm{F}$ interaction.

Results of GP and gas composition obtained from different researchers in vitro are often difficult to compare because of the influence of several confounding sources of variation. Among these, the major sources are represented by different operative conditions, such as the procedures of rumen fluid collection and treatment (Cornou et al., 2013), the type of buffer used (Patra and Yu, 2013), the ratios among feed sample size, fermentation fluid, and headspace volume (Ramin and Huhtanen, 2012), and the type of GP equipment, such as syringes or bottles that can be closed or vented at fixed times or at fixed pressure (Gierus et al., 2008; Tagliapietra et al., 2010; Pirondini et al., 2012). The magnitude of the difference of unadjusted gas composition between closed and vented bottles found in this experiment indicates that GP equipment would affect 
Table 2. Effect of gas collection technique, feed, and their interaction on the unadjusted or adjusted measures of gas production (GP, mL/g of incubated $\mathrm{DM}), \mathrm{CH}_{4}$ concentration $(\mathrm{mL} / 100 \mathrm{~mL}$ of $\mathrm{GP})$, and $\mathrm{CH}_{4}$ production $(\mathrm{mL} / \mathrm{g}$ of incubated $\mathrm{DM})$

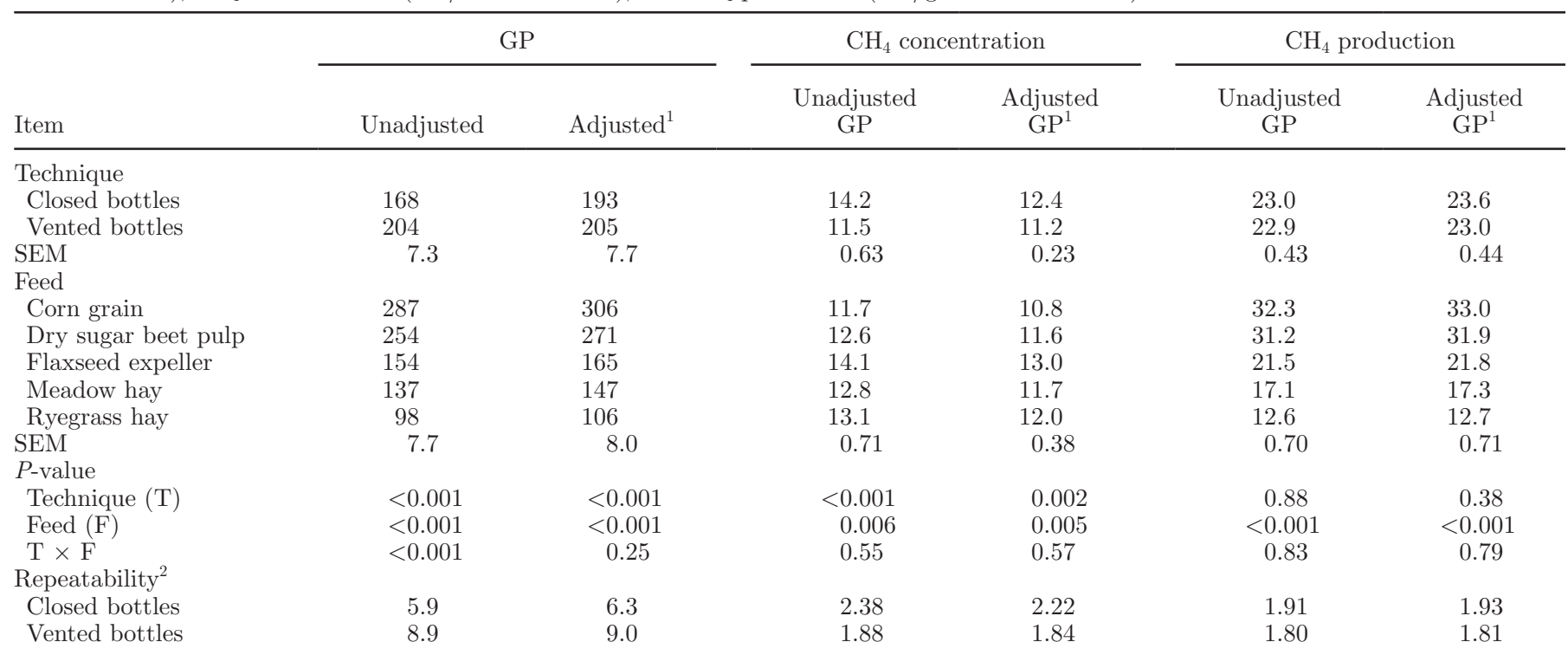

${ }^{1}$ Values of GP adjusted by adding the amount of dissolved gas computed from total gas pressure and $\mathrm{CO}_{2}$ solubility, according to Henry's law (Pell and Schofield, 1993).

${ }^{2}$ Repeatability, defined as the value below which the absolute difference between 2 single measures obtained with the same technique and under the same conditions (same incubation run, same feed) is expected with a $95 \%$ probability, was computed as $2 \sqrt{2 \sigma_{e}^{2}}$, where $\sigma_{e}^{2}$ is the residual variance (IOS, 1994).

the measured gas composition equally or more than that attributable to differences among diets or feeds. One major aspect that differentiates various GP systems concerns the different pressures generated within the fermentation units and the way by which such pressures are controlled. Despite the popularity of the various automated GP systems in use and the great effort of research done in this field, these aspects have been poorly investigated (Ramin and Huhtanen, 2012). Results of the current study show that closed bottles produced a notable underestimation of actual GP. The magnitude of this effect was small in the first phases of incubation $(<6 \mathrm{~h})$, when the headspace pressure was low, but it progressively increased at later incubation times as the headspace pressure increased (Figure 1). Moreover, the magnitude of this effect mainly depends on the ratios among headspace volume, fermentation fluid, and sample size. In the current experiment, with $0.5 \mathrm{~g}$ of feed sample, the ratio between the volume of headspace and that of fermentation fluid was 4.3 , a value greater than those frequently found in literature. This suggests that a greater underestimation of GP would be expected when smaller ratios between headspace and fermentation fluid are adopted, particularly when feeds are incubated for long times. In the vented bottles, the kinetics of GP were not influenced by the adjustment for dissolved $\mathrm{CO}_{2}$, as venting occurred when the $6.8 \mathrm{kPa}$ threshold pressure was reached. On average, valve opening occurred 2 to 3 times for hays,
4 times for flaxseed, and 7 to 8 times for corn grain and sugar beet pulp. To overcome GP underestimation due to the dissolved $\mathrm{CO}_{2}$, Pell and Schofield (1993) proposed that GP measures may be adjusted for dissolved $\mathrm{CO}_{2}$, according to Henry's law, which considers the $\mathrm{CO}_{2}$ solubility in saline solution, which may not be the same in buffered rumen fluid. In support of the results of Tagliapietra et al. (2010), our results confirm that this adjustment is not sufficient, particularly in closed systems, for a complete accounting of dissolved $\mathrm{CO}_{2}$ in the buffered rumen fluid. A further adjustment is needed, either to compensate for more dissolved $\mathrm{CO}_{2}$ than Henry's law allows or to account for differences caused by secondary interference of dissolved $\mathrm{CO}_{2}$ on rumen fermentation. This implies that caution must be made in evaluating data of gas production and composition obtained from closed bottles, as an overestimation of $\mathrm{CH}_{4}$ concentration and an underestimation of actual GP would be expected, even when an adjustment for dissolved $\mathrm{CO}_{2}$, using Henry's law, is applied. In contrast, for bottles vented at low fixed pressures, the adjustment factor for dissolved $\mathrm{CO}_{2}$ at the end of fermentation is small and results in minimal changes in the measures of GP and $\mathrm{CH}_{4}$ concentration, suggesting that equipment operating at low pressure will provide a reliable measure of both total gas and $\mathrm{CH}_{4}$ production. The main reason why closed bottles are preferred for measurements of $\mathrm{CH}_{4}$ production is that all the $\mathrm{CH}_{4}$ produced remains in the bottle headspace 
a

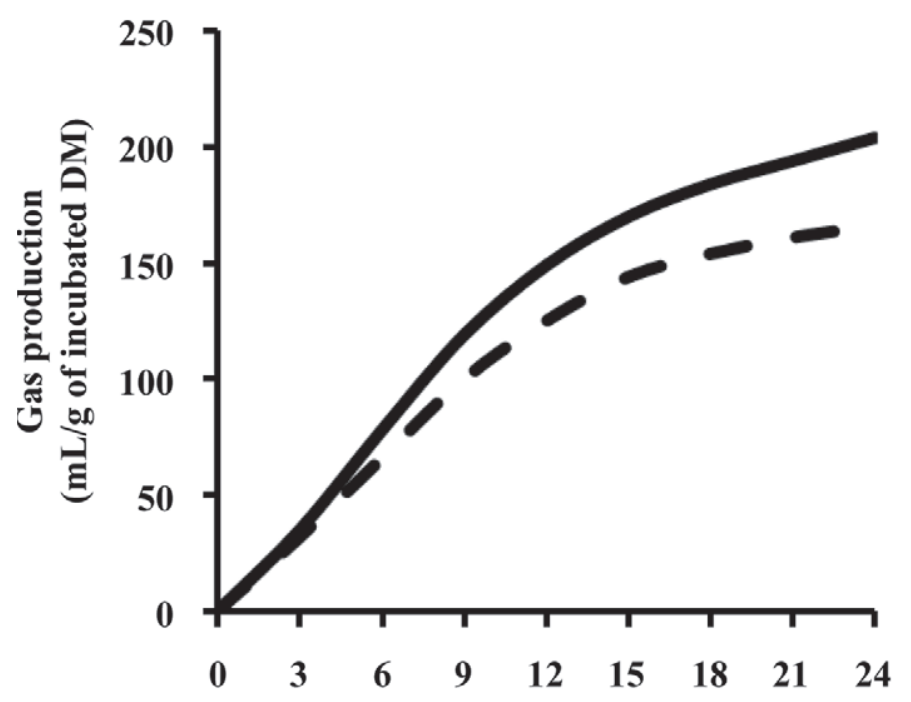

b

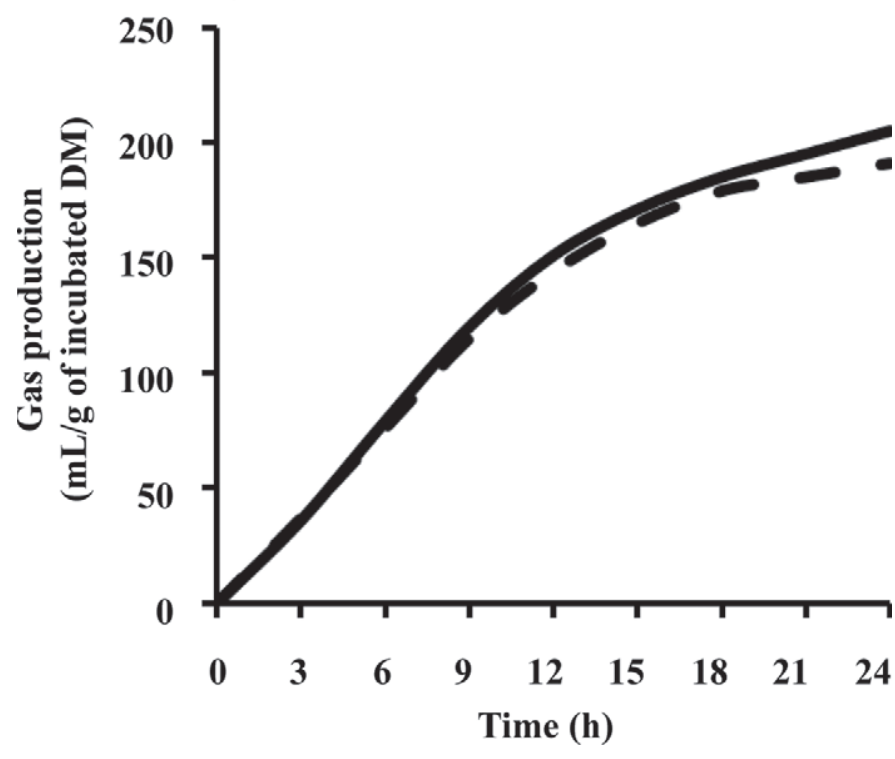

Figure 1. Gas production measurements (a) unadjusted, or (b) adjusted for dissolved $\mathrm{CO}_{2}$ in closed (dotted lines) or vented bottles (solid lines) where, in 2 incubation runs, 5 feeds were incubated in 3 replications with buffered rumen fluid for $24 \mathrm{~h}$.

(often small) without the need for the connected bag. This saves space in the incubator equipment, allowing an increased number of replications, and avoids the risk of undesired gas loss. In the current experiment, irrespective of the GP adjustment, closed and vented bottles provided similar measures of $\mathrm{CH}_{4}$ production, but only when these measures were expressed per unit of incubated DM. This was expected because, in contrast to $\mathrm{CO}_{2}$, small or negligible amounts of $\mathrm{CH}_{4}$ are dissolved in the fermentation fluid of closed bottles because of the very low $\mathrm{CH}_{4}$ solubility in water $(0.024$ $\mathrm{g} / \mathrm{L}$ at $20^{\circ} \mathrm{C}$ and $101.3 \mathrm{kPa}$ of pressure). At the same time, the lack of difference in $\mathrm{CH}_{4}$ production using the different gas collection techniques shows that gas losses from vented bottles connected to gas-tight bags used in this experiment are negligible or very low. The small or absent difference in $\mathrm{CH}_{4}$ production between closed and vented bottles may also be due to the fact that care was taken to ensure that the internal pressure in the closed bottles would not reach $45 \mathrm{kPa}$ after $24 \mathrm{~h}$ of fermentation. This value is lower than the threshold of $48 \mathrm{kPa}$ above which microbial activity can be disturbed (Theodorou et al., 1994). This was done by considering the ratios between the volume of fermentation fluid, the bottle headspace, the amount of feed incubated, and the expected GP at $24 \mathrm{~h}$ for each feed. The maximum headspace pressure found for corn samples after $24 \mathrm{~h}$ of incubation was, on average, $39 \mathrm{kPa}$. However, Patra and $\mathrm{Yu}$ (2013) demonstrated that headspace gas composition and bicarbonate concentration in the medium can affect $\mathrm{CH}_{4}$ production and other characteristics of in vitro rumen fermentation. They proposed that a greater amount of dissolved $\mathrm{CO}_{2}$ would stimulate $\mathrm{CH}_{4}$ production. Reliable measurements of in vitro total GP and $\mathrm{CH}_{4}$ would be particularly useful to explore effects of vitamins, additives, or bioactive molecules on rumen fermentation and microbial activity (Cattani et al., 2012; Hansen et al., 2012; Tagliapietra et al., 2013).

We conclude that closed systems permit reliable and comparable measurements of $\mathrm{CH}_{4}$ production per unit of incubated substrate but not reliable measurements of GP, particularly in those cases where high gas pressures are generated from feed degradation. In these cases, GP could be indirectly computed from stoichiometric relations based on VFA production after in vitro fermentation, as described by Blümmel et al. (1997), but this requires time and additional analysis and costs, and uncertainty remains due to the possible influence of dissolved $\mathrm{CO}_{2}$ on $\mathrm{CH}_{4}$ production. Use of systems based on automated venting of gas at a low pressure threshold permits a reliable evaluation of both total GP and $\mathrm{CH}_{4}$, with benefits in terms of less labor being required to control the fermentation process with respect to other semiautomated venting systems.

\section{ACKNOWLEDGMENTS}

This work was financed by the project "ARCHAEAFeeding strategies to reduce methane emissions from dairy cows," Veneto Region Rural Development Programme (RDP) 2007-2013.

\section{REFERENCES}

AOAC International. 2012. Official Methods of Analysis. 19th ed. AOAC International, Gaithersburg, MD. 
Blümmel, M., H. P. S. Makkar, and K. Becker. 1997. In vitro gas production: A technique revisited. J. Anim. Physiol. Anim. Nutr. (Berl.) 77:24-34.

Calabrò, S., S. Lopez, V. Piccolo, J. Dijkstra, M. S. Dhanoa, and J. France. 2005. Comparative analysis of gas production profiles obtained with buffalo and sheep ruminal fluid as the source of inoculum. Anim. Feed Sci. Technol. 123-124:51-65.

Cattani, M., F. Tagliapietra, L. Bailoni, and S. Schiavon. 2012. Synthetic and natural polyphenols with antioxidants properties stimulate rumen microbial growth in vitro. Anim. Prod. Sci. 52:44-50.

Cone, J. W. A. H. van Gelder, G. J. W. Visscher, and L. Oudshoorn. 1996. Influence of rumen fluid and substrate concentration on fermentation kinetics measured with a fully automated time related gas production apparatus. Anim. Feed Sci. Technol. 61:113-128.

Cornou, C., I. M. L. Drejer Storm, I. K. Hindrichsen, H. Worgan, E. Bakewell, D. R. Yánez Ruiz, L. Abecia, F. Tagliapietra, M. Cattani, C. Ritz, and H. H. Hansen. 2013. A ring test of a wireless in vitro gas production system. Anim. Prod. Sci. 53:585-592.

Davies, Z. S., D. Mason, A. E. Brooks, G. W. Griffith, R. J. Merry, and M. K. Theodorou. 2000. An automated system for measuring gas production from forages inoculated with rumen fluid and its use in determining the effect of enzymes on grass silage. Anim. Feed Sci. Technol. 83:205-221.

Getachew, G., P. H. Robinson, E. J. DePeters, S. J. Taylor, D. D. Gisi, G. E. Higginbotham, and T. J. Riordan. 2005. Methane production from commercial dairy rations estimated using an in vitro gas technique. Anim. Feed Sci. Technol. 123-124:391-402.

Gierus, M., A. Schiborra, K. H. Südekum, G. Rave, and F. Taube. 2008. Comparison of gas accumulation profiles of several feeds using manual or automated gas production methods. Anim. Feed Sci. Technol. 147:310-325.

Hansen, H. H., I. M. L. Drejer Storm, and A. M. Sell. 2012. Effect of biochar on in vitro rumen methane production. Acta Agric. Scand. Anim. Sci. 62:305-309.

ISO (International Organization for Standardization). 1994. Accuracy (trueness and precision) of measurement methods and resultsPart 2: Basic method for the determination of repeatability and reproducibility of a standard measurement method. ISO 5725-2. ISO, Geneva, Switzerland.

Lopez, S., M. S. Dhanoa, J. Dijkstra, A. Bannink, E. Kebreab, and J. France. 2007. Some methodological and analytical considerations regarding application of the gas production technique. Anim. Feed Sci. Technol. 135:139-156.

Menke, K. H., and H. Steingass. 1988. Estimation of the energetic feed value obtained from chemical analysis and gas production using rumen fluid. Anim. Res. Develop. 28:7-55.
Mertens, D. R. 2002. Gravimetric determination of amylase-treated neutral detergent fiber in feeds with refluxing in beakers or crucibles: Collaborative study. J. AOAC Int. 85:1217-1240.

Patra, A. K., and Z. Yu. 2013. Effects of gas composition in headspace and bicarbonate concentrations in media on gas and methane production, degradability, and rumen fermentation using in vitro gas production techniques. J. Dairy Sci. 96:4592-4600.

Pell, A. N., and P. Schofield. 1993. Computerized monitoring of gas production to measure forage digestion in vitro. J. Dairy Sci. 76:1063-1073.

Pellikaan, W. F., W. H. Hendriks, G. Uwimana, L. J. G. M. Bongers, P. M. Becker, and J. W. Cone. 2011. A novel method to determine simultaneously methane production during in vitro gas production using fully automated equipment. Anim. Feed Sci. Technol. 168:196-205.

Pirondini, M., L. Malagutti, S. Colombini, P. Amodeo, and G. M. Crovetto. 2012. Methane yield from dry and lactating cows diets in the Po Plain (Italy) using an in vitro gas production technique. Ital. J. Anim. Sci. 11:330-335.

Ramin, M., and P. Huhtanen. 2012. Development of an in vitro method for determination of methane production kinetics using a fully automated in vitro gas system-A modelling approach. Anim. Feed Sci. Technol. 174:190-200.

Robertson, J. B., and P. J. Van Soest. 1981. The detergent system of analysis and its application to human foods. Pages 123-158 in The Analysis of Dietary Fiber in Food. W. P. T. James and O. Theander, ed. Marcel Dekker Inc., New York, NY.

SAS Institute. 2007. SAS User's Guide: Basics. SAS Institute Inc. Cary, NC.

Tagliapietra, F., M. Cattani, L. Bailoni, and S. Schiavon. 2010. In vitro rumen fermentation: Effect of headspace pressure on the gas production kinetics of corn meal and meadow hay. Anim. Feed Sci. Technol. 158:197-201.

Tagliapietra, F., M. Cattani, H. H. Hansen, G. Bittante, and S. Schiavon. 2013. High doses of vitamin $\mathrm{E}$ and vitamin $\mathrm{C}$ influence in vitro rumen microbial activity. Anim. Feed Sci. Technol. 183:210-214.

Tagliapietra, F., M. Cattani, I. K. Hindrichsen, H. H. Hansen, S. Colombini, L. Bailoni, and S. Schiavon. 2012. True dry matter digestibility of feeds evaluated in situ with different bags and in vitro using rumen fluid collected from intact donor cows. Anim. Prod. Sci. 52:338-346.

Theodorou, M. K., B. A. Williams, M. S. Dhanoa, A. B. McAllan, and J. France. 1994. A simple gas production method using a pressure transducer to determine the fermentation kinetics of ruminant feeds. Anim. Feed Sci. Technol. 48:185-197. 